\title{
Factors associated with hip pain in end- stage renal disease patients on prevalent hemodialysis: a cross-sectional study
}

\author{
Hüma Bölük Şenlikci ${ }^{1 *} \mathbb{D}$, Sevgi İkbali Afşar ${ }^{1}$, Selin Özen ${ }^{1}$ and Cihat Burak Sayın²
}

\begin{abstract}
Background: Hemodialysis (HD) patients suffer from musculoskeletal disorders. The most reported musculoskeletal problem is arthralgia. Hip arthralgia has been commonly reported in patients undergoing HD. Hip pain can lead to a decrease in levels of physical activity, limitation in joint range of motion, and consequently difficulties in performing activities of daily living (ADL) and impair the quality of life (QoL). The aim of the study is to reveal the prevalence of hip pain and related factors in HD patients. This cross-sectional study included 73 patients on prevalent HD whose ages ranged from 25 to 65 years and who were on HD for more than 6 months. Physical examination and radiological imaging were done to every patient. Visual analog scale, Barthel Index, and Short Form-36 were used to evaluate pain, ADL, and QoL, respectively.

Results: Hip arthralgia was detected in 32 patients. Around 43\% of which were diagnosed hip osteoarthritis, 34\% greater trochanteric pain syndrome, 15\% femoroacetabular impingement, and $6 \%$ soft tissue calcifications. Diabetes mellitus and hemodialysis duration were found to be significantly different between the groups of hip pain and without hip pain. Diabetes mellitus was identified as an independent risk factor for hip pain in hemodialysis patients. ADL and QoL were significantly lower in patients with hip pain compared to those without $(p<0.01 ; p<$ 0.05 , respectively).

Conclusions: The results of our research show that HD patients should be screened for the presence of hip pain and other musculoskeletal disorders and that this is an area which requires further consideration and medical research.
\end{abstract}

Keywords: Renal dialysis, Musculoskeletal pain, Osteoarthritis, Chronic kidney failure

\section{Background}

End-stage renal disease patients undergoing hemodialysis (HD) suffer from various symptoms related to many organ systems. Some of these are musculoskeletal dysfunction and pain. As much as $80 \%$ of patients undergoing HD have chronic musculoskeletal pain, particularly arthralgia [1]. Approximately $40 \%$ of $\mathrm{HD}$ patients have previously

\footnotetext{
* Correspondence: humaboluk@gmail.com

${ }^{1}$ Department of Physical Medicine and Rehabilitation, Başkent University

Faculty of Medicine, Ankara, Turkey

Full list of author information is available at the end of the article
}

reported lower extremity pain [2]. Hip pain is one of the causes of musculoskeletal pain in patients undergoing HD. Osteoarthritis, inflammatory arthritis, greater trochanteric pain syndrome (GTPS), avascular necrosis, femoroacetabular impingement (FAI), and osteoporosis resulting in fractures are among the most common causes of hip pain in the general population [3, 4]. Hip pain can lead to a decrease in levels of physical activity, muscle weakness, limitation in joint range of motion, and consequently difficulties in performing activities of daily living (ADL) and quality of life (QoL) [5].

Hip pain and other musculoskeletal symptoms are overlooked as serious problems of HD patients. The aim

\section{Springer Open}

(c) The Author(s). 2021 Open Access This article is licensed under a Creative Commons Attribution 4.0 International License, which permits use, sharing, adaptation, distribution and reproduction in any medium or format, as long as you give appropriate credit to the original author(s) and the source, provide a link to the Creative Commons licence, and indicate if changes were made. The images or other third party material in this article are included in the article's Creative Commons licence, unless indicated otherwise in a credit line to the material. If material is not included in the article's Creative Commons licence and your intended use is not permitted by statutory regulation or exceeds the permitted use, you will need to obtain permission directly from the copyright holder. To view a copy of this licence, visit http://creativecommons.org/licenses/by/4.0/. 
of the present study is to evaluate the prevalence and features of hip pain and to reveal related factors and effects on health-related quality of life in hemodialysis patients.

\section{Method}

\section{Study design and participants}

A cross-sectional study of patients with end-stage renal disease receiving $\mathrm{HD}$ at the Başkent University Faculty of Medicine, Hemodialysis Units, Ankara, Turkey. The study was conducted between 2019 January and 2020 January. Patients aged between 25 and 65 years undergoing HD for more than 6 months, three times a week, who did not have acute infection and cognitive impairment and had stable general condition were included in the study. Patients were questioned regarding symptoms of anterior and lateral hip pain or pain in the groin. Patients who had a history of rheumatologic disorders, cerebrovascular disease, total hip replacement, uncontrollable systemic disease, active cancer, and cognitive impairment and those who did not agree to participate in the trial were excluded from the study. As a result, a total of 73 patients (32 patients with hip pain and 41 without) were included in the study.

The study was performed in accordance with the Declaration of Helsinki. It was approved by the Ethics committee of Başkent University approval number KA18/248. Written informed consent was obtained from all participants.

\section{Data collection}

Demographic and clinical data such as age, gender, body mass index (BMI), HD duration, and co-morbidities (hypertension (HT), diabetes mellitus (DM), and cardiac disease (CD)) were collected during a face-to-face interview conducted by a physician. At the time of the interview, patients were also questioned on the presence of hip pain. In those with complaints of hip pain, duration, characteristics, localization, and spread of the pain were questioned. Pain severity was assessed using the VAS and classified as mild (0-4), moderate (5-7), and severe (8-10). Pain lasting more than 3 months was classified as chronic pain and pain of less than 3-month duration was classified as acute pain.

All patients then underwent a detailed physical examination. Laboratory parameters as serum calcium, phosphate, alkaline phosphatase (ALP), parathyroid hormone, and 25-cholecalciferol levels were recorded.

\section{Outcome measures}

\section{Short Form-36}

The Short Form-36 (SF-36) is used to assess healthrelated QoL. The SF-36 consists of 36 items in 2 parts: mental and physical. The physical role, emotional role, physical function, energy/vitality, mental health, social function, pain, and general health are subgroups of assessment. Scores range from 0 to 100, with higher scores indicating a better health-related quality of life. The validity and reliability of the SF-36 has previously been studied [6].

\section{Barthel Index}

The Barthel Index is used to assess performance in ADL. Higher scores indicate greater ability of functional independence. The Barthel Index consists of ten personal activities: feeding, toileting, dressing and undressing, getting on and off the toilet, bladder-bowel control, transfers from bed to wheelchair and back, walking or using a wheelchair on a flat ground, and ascendingdescending stairs [7].

\section{Visual analog scale}

A $10-\mathrm{cm}$ visual analog scale (VAS) was used to assess the pain. Patients were asked to score the intensity of their pain $[8,9]$.

\section{Examination of hip pain}

Physical examination of the hip was performed in all study participants beginning with an inspection followed by palpation of the greater trochanter and iliotibial band, joint range of motion (ROM), and gait evaluation. Specific tests such as the flexion abduction external rotation (FABER) test and flexion adduction internal rotation (FADIR) test were performed. Gait abnormalities, such as the presence of the Trendelenburg gait or an antalgic gait, were recorded. Neurological examination including sensory-motor examination and eliciting lower extremity deep tendon reflexes was performed. The straight leg raise test and femoral nerve stretch test were performed to rule out lumbar pathologies.

All patients with hip pain were evaluated radiologically. For a definitive diagnosis, X-ray and magnetic resonance imaging (MRI) were performed to identify the etiology of hip pain.

The diagnosis of hip osteoarthritis (OA) was made according to The American College of Rheumatology classification criteria [10]. The X-ray of each hip was scored using the Kellgren and Lawrence scale which is used to grade the stage of osteoarthritis: grade 0 refers to a normal joint, grade 1 refers to possible osteophytes with normal joint space, grade 2 refers to a possible narrowing of the joint space with definite osteophytes, grade 3 refers to a definite narrowing of the joint space, and finally grade 4 refers to a marked narrowing of the joint space, possible cysts or sclerosis and usually osteophytes [11].

A patient received a diagnosis of greater trochanteric pain syndrome (GTPS) in the presence of lateral hip pain and/or distinct tenderness around the greater 
trochanter plus at least one of the following criteria: (1) pain at the extremes of hip rotation, abduction, or adduction; (2) pain on hip abduction against resistance; (3) tenderness over the gluteus medius muscle; (4) a positive FABER test; and (5) pain radiating down the lateral aspect of the thigh (pseudoradiculopathy). X-ray imaging was also used for differential diagnosis of these patients [12, 13].

Femoroacetabular impingement is also one of the most commonly occurring causes of hip pain. FAI was diagnosed in patients who described chronic, deep, and anterior groin pain while sitting or during activity and had positive FABER and FADIR tests. Over $90^{\circ}$ hip flexion was limited or painful. A definitive diagnosis was made using X-ray imaging and MRI of the hip. On anteroposterior radiography, increased acetabular depth and/or presence of the crossover sign for focal acetabular retroversion and/or $>40^{\circ}$ lateral center edge angle were detected. MRI was used in cases of doubt [14].

\section{Statistical analysis}

Statistical analyses were carried out using the SPSS version 20.0 software for Windows (IBM SPSS Inc., Chicago, IL). Conformity of the data to the normal distribution was assessed using the Kolmogorov-Smirnov test. The mean \pm standard deviation (SD) of normally distributed data was provided. Median (minimum-maximum) values of non-normally distributed data were provided. Categorical data was shown in numbers (n) and percentages (\%). The chi-square test and Fischer's exact test were applied to categorical data. Betweengroup evaluation of normally distributed data was performed using the t-test. Non-normally distributed data was compared using the Mann-Whitney $U$ test. Variables with a $p$ value less than 0.25 were included in the multivariable regression model. The predictive value of the Barthel Index score was determined by the Youden index method of ROC curve analysis. A value of $p \leq 0.05$ was accepted as statistically significant. Spearman's rho correlation test was used for categorical non-parametric evaluations with the Pearson correlation test.

\section{Results}

In total, 41 male (56.2\%) and 32 female (43.8\%) patients were included in the study (mean age $54.4 \pm 11.3$ ). The median HD duration was 5 years (interquartile range $0.5-30$ years $)$. Approximately $45 \%(n=33)$ of the patients had hypertension, 24.7\% $(n=18)$ had diabetes mellitus, and $16.4 \%(n=12)$ had coronary artery disease. A total of 32 patients undergoing HD (43.2\%) had hip pain. Eighteen patients had previously been seen by a physical medicine and rehabilitation, rheumatology, and orthopedics specialist for the hip pain; the remaining 14 patients had never been evaluated by a physician due to hip pain. Other sociodemographic and clinical characteristics of the study participants are shown in Table 1 . In the group comparisons, the number of patients with diabetes mellitus and those who had been receiving HD for more than 10 years was significantly greater in the hip pain group ( $37.5 \%$ vs $14.6 \%, p=0.031$; $43.8 \%$ vs $17.1 \%, p=0.019$, respectively). There was no significant difference between group difference in other clinical characteristics, demographic findings, and laboratory parameters (Table 1).

The outcomes of patients undergoing HD with hip pain are presented in Table 2. According to the VAS scores for hip pain, 12 patients had mild pain (37.5\%), 14 patients had moderate pain $(43.7 \%)$, and 6 patients had severe pain (18.7\%). The majority of the patients had chronic hip pain (90.6\%). Nearly half of the participants reported bilateral hip pain $(46.9 \%)$, and $31.3 \%$ of the patients reported pain in the right hip. On hip joint examination, FADIR and FABER test positivity was detected in twenty and twenty-seven of the 73 patients, respectively. Tenderness by palpation was found in 14 patients. Limitation in hip range of motion was present in 11 patients. The etiology of the hip pain was osteoarthritis in 14 patients (43.6\%) and GTPS in 11 patients (34.3\%), 5 patients were diagnosed with FAI (15.6\%), and the remaining $2(6.2 \%)$ had soft tissue calcification. According to the Kellgren and Lawrence scale, the majority of the patients had grade 3 osteoarthritis (57.1\%) of the hip (Table 2).

The Barthel Index scores were significantly lower in patients with hip pain than in those without $(88.1 \pm 14.5$ vs $98.5 \pm 3.0 ; p<0.001)$. All SF-36 subgroup scores were significantly lower in patients with hip pain (Table 3).

Variables that may be of clinical significance in patients with hip pain are shown in Table $4(p<0.25)$. Sociodemographic and clinical characteristics of the patients were included in the multivariate logistic regression; diabetes mellitus was identified as an independent risk factor for hip pain in HD patients $(\mathrm{OR}=3.91 ; p=$ 0.030) (Table 4).

The predictive value of Barthel Index at 95\% CI showed sensitivity $68.8 \%$ and specificity $78.1 \%$ for hip pain (+LR 5.9; -LR 0.6; +PV 71\%; -165 PV 76.2\%) (Fig. 1).

There was no statistically significant correlation between hip pain VAS scores and vitamin D and PTH levels $(\mathrm{r}=-0.013, p=0.916 ; \mathrm{r}=0.091, p=0.442$, respectively).

\section{Discussion}

The aim of this study was to evaluate the prevalence of hip pain in hemodialysis patients and investigate its effects on ADL and health-related QoL. The frequency of OA and GTPS was higher in hemodialysis patients when compared to previous studies of the general population. The frequency of FAI was similar to that of the general 
Table 1 Demographic and clinical characteristics of the hemodialysis patients

\begin{tabular}{|c|c|c|c|c|}
\hline & \multirow{2}{*}{$\begin{array}{l}\text { All } \\
\text { population } \\
n=73\end{array}$} & \multicolumn{2}{|c|}{ Hip pain in HD patients } & \multirow[t]{2}{*}{$P$} \\
\hline & & $\begin{array}{l}\text { With hip pain } \\
n=32\end{array}$ & $\begin{array}{l}\text { Without hip pain } \\
n=41\end{array}$ & \\
\hline Age, years & $54.4 \pm 11.3$ & $54.0 \pm 11.5$ & $54.8 \pm 11.2$ & $0.771^{*}$ \\
\hline \multicolumn{5}{|l|}{ Gender, n (\%) } \\
\hline Female & $32(43.8)$ & $18(56.3)$ & $14(34.1)$ & \multirow[t]{2}{*}{$0.095^{* *}$} \\
\hline Male & $41(56.2)$ & $14(43.8)$ & $27(65.9)$ & \\
\hline BMI, $\mathrm{kg} / \mathrm{m}^{2}$ & $26.0 \pm 6.2$ & $26.5 \pm 7$ & $25.6 \pm 5.6$ & $0.553^{*}$ \\
\hline HD duration, years & $5(0.5-30.0)$ & $9(0.5-30)$ & $4(0.5-24)$ & $0.171^{* *}$ \\
\hline$<10$ years & $52(71.2)$ & $18(56.3)$ & $34(82.9)$ & $0.019^{* *}$ \\
\hline$>10$ years & $21(28.8)$ & $14(43.8)$ & $7(17.1)$ & \\
\hline \multicolumn{5}{|l|}{ Co-morbidities } \\
\hline HT, n (\%) & $33(45.2)$ & $13(40.6)$ & $20(48.8)$ & $0.636^{* *}$ \\
\hline $\mathrm{DM}, \mathrm{n}(\%)$ & $18(24.7)$ & $12(37.5)$ & $6(14.6)$ & $0.031^{* *}$ \\
\hline CD, n (\%) & $12(16.4)$ & $5(15.6)$ & $7(17.1)$ & $0.999 * *$ \\
\hline \multicolumn{5}{|l|}{ Laboratory parameters } \\
\hline Calcium (mg/dL) & $8.6 \pm 0.8$ & $8.5 \pm 0.7$ & $8.7 \pm 1.0$ & $0.414^{*}$ \\
\hline Phosphate (mg/dL) & $5.2 \pm 1.3$ & $5.1 \pm 1.1$ & $5.3 \pm 1.4$ & $0.589^{*}$ \\
\hline PTH $(p g / m L)$ & $461(1.5-2460)$ & $493.2(1.5-2000)$ & $427(8.5-2460)$ & $0.443^{*}$ \\
\hline Vitamin D (ng/mL) & $13(1.0-62.7)$ & $14.3(3.5-49.2)$ & $12.7(1-62.7)$ & $0.831^{*}$ \\
\hline$<20 \mathrm{ng} / \mathrm{mL}$ & $54(74.0)$ & $24(75.0)$ & $30(73.2)$ & $0.999^{*}$ \\
\hline $\mathrm{ALP}(\mathrm{IU} / \mathrm{mL})$ & $118(39-950)$ & $140.5(63-880)$ & $99(39-950)$ & $0.059^{*}$ \\
\hline
\end{tabular}

$B M I$ body mass index, DM diabetes mellitus, $H T$ hypertension, $C D$ cardiac disease, $H D$ hemodialysis, $P T H$ parathyroid hormone, ALP alkaline phosphatase ${ }^{*}$ Chi-square test, $\mathrm{p} \leq 0.05$ was accepted as statistically significant; ${ }^{*}$ Mann-Whitney $\mathrm{U}$ test

population (10-15\%) [15-18]. ADL and health-related QoL scores were significantly lower in those with hip pain.

Diabetes mellitus and hemodialysis duration were significant factors affecting the presence of hip pain. Moreover, diabetes mellitus was identified as an independent risk factor for hip pain.

Chronic pain is a common problem in HD patients and may occur in the form of headaches, arteriovenous fistula-related pain, widespread body pain, and musculoskeletal pain [19]. Musculoskeletal pain is the main cause of chronic pain in HD patients [20]; arthralgia secondary to osteoarthritis has been reported in $83 \%$ of patients $[1,20]$. Hip pain occurs less commonly and is present in $7.5-18 \%$ of HD patients $[1,20-22]$. In our study, the prevalence of hip pain was higher than previously reported in HD patients; this may be due to several reasons. Firstly, the mean age of the patient population of our study was greater than that in previous studies [22]. Secondly, in our study, the duration of dialysis was longer in patients with hip pain when compared to those without. Similarly, dialysis duration in the patients of our study was longer than that in previous studies [20]. In addition, the patients in the aforementioned study were evaluated only in terms of hip OA; $53.9 \%$ of those with hip pain had OA. Hence, this finding is in line with the prevalence of hip OA in our study.

Greater trochanteric pain syndrome is one of the common causes of hip pain. Patients mostly complain of pain radiating from the hip to the upper lateral aspect of the leg; however, the presence of tenderness around the greater trochanter without lateral leg pain may also be a sign of GTPS. In a study in which stroke patients with normal cognitive function were investigated in terms of GTPS, pain emerged with maneuvers that constitute the diagnostic criteria of GTPS in asymptomatic patients, and a diagnosis of GTPS was made based on these finding at a rate of $19 \%$ [15]. In our study, patients were evaluated for the presence of GTPS, and 11 GTPS diagnoses were made using direct radiography, excluding other diagnoses.

Other possible reasons for the high prevalence of hip pain in our study may be that all study participants were examined for signs of GTPS and FAI, rather than just those with symptoms of hip pain, and unlike in some other studies, all diagnoses were supported by imaging methods $[1,16,20]$.

In our study, DM was identified as an independent risk factor for hip pain in HD patients. DM has previously been defined as a risk factor for chronic musculoskeletal 
Table 2 Clinical characteristics of the hemodialysis patients with hip pain

\begin{tabular}{ll}
\hline & $\begin{array}{l}\text { HD patients with } \\
\text { hip pain }(\boldsymbol{n}=\mathbf{3 2}) \\
\mathbf{n}(\%)\end{array}$ \\
\hline VAS value & $12(37.5)$ \\
0-4: mild & $14(43.7)$ \\
5-7: moderate & $6(18.7)$ \\
8-10: severe & \\
Duration of pain & $3(9.4)$ \\
Acute $<3$ months & $29(90.6)$ \\
Chronic > 3 months & \\
Side of pain & $10(31.3)$ \\
Right & $7(21.9)$ \\
Left & $15(46.9)$ \\
Bilaterally & \\
Etiology of pain, $\mathbf{n}$ (\%) & $14(43.8)$ \\
Osteoarthritis & $11(34.3)$ \\
GTPS & $5(15.6)$ \\
FAl & $2(6.2)$ \\
Soft tissue or tendon calcification & \\
Kellgren and Lawrence scores & $2(14.3)$ \\
Grade 1 & $2(14.3)$ \\
Grade 2 & $8(57.1)$ \\
Grade 3 & $2(14.3)$ \\
Grade 4 & \\
\hline
\end{tabular}

HD hemodialysis, VAS visual analog scale, GTPS greater trochanteric pain syndrome, FAl femoroacetabular impingement

Table 3 Comparison of Barthel Index scores and SF-36 subgroup scores between HD patients with and without hip pain

\begin{tabular}{llll}
\hline & \multicolumn{2}{l}{ Hip pain in HD patients } & $p$ \\
\cline { 2 - 3 } & $\begin{array}{l}\text { With hip pain } \\
\boldsymbol{n}=\mathbf{3 2}\end{array}$ & $\begin{array}{l}\text { Without hip pain } \\
\boldsymbol{n}=\mathbf{4 1}\end{array}$ & \\
\hline $\begin{array}{l}\text { Barthel Index scores } \\
\text { SF-36 subgroup scores }\end{array}$ & $88.1 \pm 14.5$ & $98.5 \pm 3.0$ & $<0.001^{*}$ \\
Physical function & $42.5(0-90)$ & $80(15-100)$ & $<0.001^{*}$ \\
Physical role & $75(0-100)$ & $75(0-100)$ & $0.004^{*}$ \\
Emotional role & $66.7(0-100)$ & $100(0-100)$ & $0.004^{*}$ \\
Energy/vitality & $48.9 \pm 13.2$ & $57.2 \pm 11.5$ & $0.005^{*}$ \\
Mental health & $61.1 \pm 8.5$ & $66.6 \pm 9.8$ & $0.014^{*}$ \\
Social function & $56.6 \pm 17.7$ & $73.8 \pm 16.5$ & $<0.001^{*}$ \\
General pain & $56.3(0-100)$ & $77.5(22.5-100)$ & $<0.001^{*}$ \\
General health & $45(10-65)$ & $55(20-80)$ & $<0.001^{*}$ \\
\hline
\end{tabular}

HD hemodialysis, SF-36 Short Form-36

${ }^{*}$ Chi-square test, $\mathrm{p} \leq 0.05$ was accepted as statistically significant
Table 4 Multivariate analysis of risk factors for hip pain in HD patients

\begin{tabular}{llll}
\hline & OR & $\mathbf{9 5 \% ~ C l}$ & $\boldsymbol{p}$ \\
\hline Diabetes mellitus & 3.91 & $1.17-13.05$ & $0.030^{*}$ \\
\hline
\end{tabular}

$O R$ odds ratio, $C l$ confidence interval

*Logistic regression analysis

pain in HD patients [23] and has been associated with tendinopathy, arthralgia, septic arthritis, and bone loss resulting in fractures of the hip joint [16, 23-25]. Previous studies have also shown that HD patients who have arthralgia have a poor QoL [26]; a relationship between many musculoskeletal system findings, poor physical function, and QoL has been identified [22, 26]. In our study, both mental and physical QoL scores of HD patients with hip pain were lower than those without hip pain.

When we compared the two groups in terms of laboratory parameters, there was no correlation between parathyroid hormone (PTH) levels and hip pain severity in HD patients. Similarly, no relationship was found between PTH level and chronic musculoskeletal pain in a study involving HD patients [16]. However, there are also studies claiming the opposite [27]. In the aforementioned study, bone pain was found to be associated with secondary hyperparathyroidism; however, a higher PTH level is not the only indicator of secondary hyperparathyroidism [27]. In our study, patients were not examined for secondary hyperparathyroidism. Therefore, it is not surprising that there was no direct relationship between hip pain and PTH level.

Another finding in our study was that there was no correlation between vitamin D levels and hip pain severity in HD patients. Additionally, when the groups with and without hip pain were compared in terms of vitamin D levels, no significant difference was found between them. In previous studies, a relationship was found between vitamin $\mathrm{D}$ level and musculoskeletal pain in healthy individuals $[28,29]$. No such relationship was found in HD patients [30, 31]. Our findings appear to be in accordance with the literature. Half of the patients with hip pain in our study consisted of patients with hip OA. The relationship between vitamin D and osteoarthritis has been the subject of many previous studies; no correlation has been found between OA and vitamin D levels [32, 33], but some studies have shown a relationship between OA progression and vitamin D levels [34]. To date, studies in this area have not been conducted on HD patients.

In our study, the most common etiology of hip pain was OA, followed by GTPS and FAI. There are no studies evaluating the relationship between GTPS, FAI, and vitamin D in hemodialysis patients in the literature. 


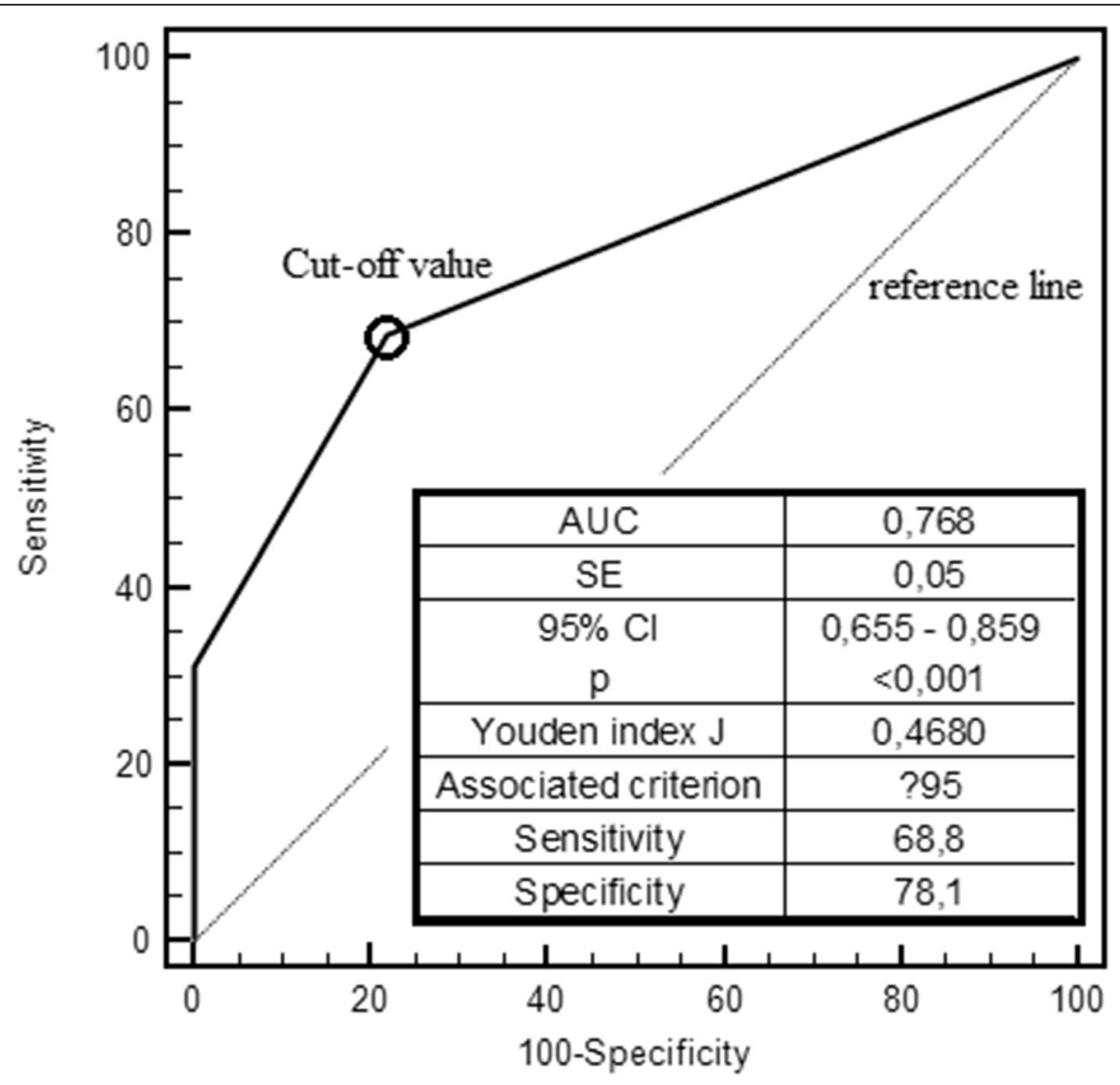

Fig. 1 Diagnostic performance assessment of Barthel Index score in HD patients with hip pain. AUC area under the ROC curve, SE standard error, $\mathrm{Cl}$ confidence interval

To the best of our knowledge, there are no studies to date which have evaluated hip pain alone in HD patients. The main limitations of the study are its cross-sectional design which did not allow the causality of the associations to be examined and the possibility that musculoskeletal pain due to polyneuropathy may have been confused with the musculoskeletal diagnosis. Another limitation is that patients were not investigated in terms of osteoporosis; this can be investigated using dual-energy X-ray absorptiometry in future studies. Finally, another limitation of this study included the small number of patients and not measuring the role of vitamin $\mathrm{D}$ deficiency on hip pain.

However, the use of radiological imaging further supported the diagnosis in those with GTPS, FAI, and OA. Conducting MRI of the hip in all patients to support the clinical diagnosis of the cause of hip pain may be considered in future studies. Although expensive, limiting the use of MRI may have overlooked diagnoses such as early avascular necrosis, amyloid deposits, crystal-induced arthropathies, deformities, and insufficiency fractures related to bone and mineral disturbance commonly encountered in patients on dialysis.

\section{Conclusion}

The findings of this study indicate that hip pain is more common in HD patients compared to the general population and that DM is an independent risk factor for hip pain in this patient group. The presence of hip pain also had a negative impact on ADL and QoL. The results of our research show that HD patients should be screened for the presence of hip pain and other musculoskeletal disorders and that this is an area which requires further consideration and medical research.

\section{Abbreviations}

CD: Cardiac disease; DM: Diabetes mellitus; FABER: Flexion abduction external rotation; FADIR: Flexion adduction internal rotation; FAl: Femoroacetabular impingement; GTPS: Great trochanteric pain syndrome; HD: Hemodialysis; HT: Hypertension; MRI: Magnetic resonance imaging; OA: Osteoarthritis; PTH: Parathyroid hormone; QoL: Quality of life; ROM: Range of motion; SF36: Short Form-36; VAS: Visual analog scale

\section{Acknowledgements} Not applicable 


\section{Authors' contributions}

HBŞ and SIA: data collection, writing, and supervision. SO and CBS: statistical analyses, supervision, critical analyses, and data collection. All authors have read and approved the final manuscript.

\section{Funding}

No financial support has been received.

\section{Availability of data and materials}

Data is available.

\section{Declarations}

\section{Ethics approval and consent to participate}

The study was approved by the Ethical Committee of Başkent University Medical School (Project number: KA18/248).

Written informed consent was given from all participants.

\section{Consent for publication}

Not applicable

\section{Competing interests}

The authors declare that they have no competing interests.

\section{Author details}

'Department of Physical Medicine and Rehabilitation, Başkent University Faculty of Medicine, Ankara, Turkey. '2Department of Nephrology, Başkent University Faculty of Medicine, Ankara, Turkey.

\section{Received: 22 February 2021 Accepted: 1 June 2021}

\section{Published online: 01 July 2021}

\section{References}

1. Afifi WM, Abo Elsaoud AM, Elgawish MH, Ghorab AM (2019) Musculoskeletal manifestations in end-stage renal disease patients on hemodialysis and relation to parathyroid dysfunction. Saudi J Kidney Dis Transpl. 30(1):68-82. https://doi.org/10.4103/1319-2442.252935

2. Yeşil S, Karslı B, Kayacan N, Süleymanlar G, Ersoy F (2015) Pain evaluation in patients with chronical renal failure undergoing hemodialysis. Agri. 27(4): 197-204. https://doi.org/10.5505/agri.2015.44712

3. Hanudel MR, Froch L, Gales B, Jüppner H, Salusky IB (2017) Fractures and osteomalacia in a patient treated with frequent home hemodialysis. Am J Kidney Dis. 70(3):445-448. https://doi.org/10.1053/j.ajkd.2017.03.015

4. Kart-Köseoglu H, Yucel AE, Niron EA, Köseoglu H, Isiklar I, Ozdemir FN (2005) Osteoarthritis in hemodialysis patients: relationships with bone mineral density and other clinical and laboratory parameters. Rheumatol Int. 25(4): 270-275. https://doi.org/10.1007/s00296-003-0431-z

5. Hampton SN, Nakonezny PA, Richard HM, Wells JE. (2019) Pain catastrophizing, anxiety, and depression in hip pathology. Bone Joint J.101B:800-807.

6. Kocyigit H, Aydemir O, Fisek G, Olmez N, Memiş A (1999) Validity and reliability of Turkish version of Short form 36: a study of a patients with rheumatoid disorder. (in Turkish) J. Drug Ther 2:102-106

7. Küçükdeveci AA, Yavuzer G, Tennant A, Süldür N, Sonel B, Arasil T (2000) Adaptation of the modified Barthel index for use in physical medicine and rehabilitation in Turkey. Scandinavian Journal of Rehabilitation Medicine 32(2):87-92

8. Wewers ME, Lowe NK. (1990) A critical review of visual analogue scales in the measurement of clinical phenomena. Res Nurs Health.13:227-36.

9. Collins SL, Moore RA, McQuay HJ (1997) The visual analogue pain intensity scale: what is moderate pain in millimetres? Pain 72(1):95-97. https://doi. org/10.1016/S0304-3959(97)00005-5

10. Altman R, Alarcón $G$, Appelrouth D, Bloch D, Borenstein D, Brandt K, Brown C, Cooke TD, Daniel W, Feldman D, Greenwald R, Hochberg M, Howell D, Ike R, Kapila P, Kaplan D, Koopman W, Marino C, McDonald E, McShane DJ, Medsger T, Michel B, Murphy WA, Osial T, Ramsey-Goldman R, Rothschild B, Wolfe F (1991) The American College of Rheumatology criteria for the classification and reporting of osteoarthritis of the hip. Arthritis Rheum. 34(5):505-514. https://doi.org/10.1002/art.1780340502

11. Kellgren JH, Lawrence JS (1963) Atlas of standard radiographs of arthritis. The epidemiology of chronic rheumatism. Blackwell, Oxford
12. Geraci A, Sanfilippo A, D’Arienzo M (2011) Greater trochanteric pain syndrome: what is this meaning. Orthopedic Muscul Sys.:2161-0533

13. Ganderton C, Semciw A, Cook J, Pizzari T (2017) Demystifying the clinical diagnosis of greater trochanteric pain syndrome in women. J Womens Health (Larchmt). 26(6):633-643. https://doi.org/10.1089/jwh.2016.5889

14. Zhang C, Li L, Forster BB, Kopec JA, Ratzlaff C, Halai L, Cibere J, Esdaile JM (2015) Femoroacetabular impingement and osteoarthritis of the hip. Can Fam Physician. 61(12):1055-1060

15. Köseoğlu BF, Kesikburun B, Oken O (2014) Greater trochanteric pain syndrome: frequency and associated factors in patients with stroke. Top Stroke Rehabil. 21(5):383-390. https://doi.org/10.1310/tsr2105-383

16. Hsu HJ, Yen CH, Hsu KH, Wu IW, Lee CC, Hung MJ, et al. (2014) Factors associated with chronic musculoskeletal pain in patients with chronic kidney disease. BMC Nephrol.15:6

17. Cibulka MT, Bloom NJ, Enseki KR, Macdonald CW, Woehrle J, McDonough CM (2017) Hip pain and mobility deficits-hip osteoarthritis: revision 2017. J Orthop Sports Phys Ther. 47(6):A1-A37. https://doi.org/1 0.2519 /jospt.2017.0301

18. Tepeli B, Uzunkulaoglu A (2016) Femoroacetabular impingement syndrome: review. J PMR sci 19:179-185

19. Brkovic T, Burilovic E, Puljak L (2018) Risk factors associated with pain on chronic intermittent hemodialysis: a systematic review. Pain Pract. 18(2):247268. https://doi.org/10.1111/papr.12594

20. Hage S, Hage V, El-Khoury N, Azar H, Chelala D, Ziadé N (2020) Musculoskeletal disorders in hemodialysis patients: different disease clustering according to age and dialysis duration. Clin Rheumatol. 39(2): 533-539. https://doi.org/10.1007/s10067-019-04786-w

21. Kesikburun B, Ekşioğlu E, Akdağ I, Çakçı A (2017) Low back pain in hemodialysis patients: risk factors and its impact on health-related quality of life. Turk J Phys Med Rehabil. 64(1):66-71. https://doi.org/10 5606/tftrd.2018.1016

22. El-Najjar RA, Amar HA, El wahab Selim HA, Ibrahem M, Fouad M. (2014) Musculoskeletal disorders in hemodialysis patients and its impact on physical function (Zagazig University Nephrology Unit, Egypt). Egyptian Rheumatology and Rehabilitation 41(4):152-159. https://doi.org/10.4103/111 0-161X.147356

23. Kaka B, Maharaj SS, Fatoye F (2019) Prevalence of musculoskeletal disorders in patients with diabetes mellitus: a systematic review and meta-analysis. J Back Musculoskelet Rehabil. 32(2):223-235. https://doi. org/10.3233/BMR-171086

24. Lui PPY (2017) Tendinopathy in diabetes mellitus patients-epidemiology, pathogenesis, and management. Scand J Med Sci Sports. 27(8):776-787. https://doi.org/10.1111/sms.12824

25. Ferrari SL, Abrahamsen B, Napoli N, Akesson K, Chandran M, Eastell R, el-Hajj Fuleihan G, Josse R, Kendler DL, Kraenzlin M, Suzuki A, Pierroz DD, Schwartz AV, Leslie WD, Bone and Diabetes Working Group of IOF (2018) Bone and Diabetes Working Group of IOF. Diagnosis and management of bone fragility in diabetes: an emerging challenge. Osteoporos Int. 29(12):25852596. https://doi.org/10.1007/s00198-018-4650-2

26. Fidan F, Alkan BM, Tosun A, Altunoğlu A, Ardıçoğlu Ö. (2016) Quality of life and correlation with musculoskeletal problems, hand disability and depression in patients with hemodialysis. Int J Rheum Dis.19:159-166.

27. Hawley CM, Holt SG (2017) Parathyroid hormone targets in chronic kidney disease and managing severe hyperparathyroidism. Nephrology (Carlton). 22:47-50. https://doi.org/10.1111/nep.13029

28. Wintermeyer E, Ihle C, Ehnert S, Stöckle U, Ochs G, de Zwart P, Flesch I, Bahrs C, Nussler A (2016) Crucial role of vitamin D in the musculoskeletal system. Nutrients. 8(6):319-334. https://doi.org/10.3390/nu8060319

29. Rader, C.P, Corsten, N, Rolf, O. (2015) Osteomalacia and vitamin D deficiency. Orthopade. 44:695-702.

30. Jean G, Souberbielle JC, Chazot C (2017) Vitamin D in chronic kidney disease and dialysis patients. Nutrients. 9(4):328-343. https://doi.org/10.33 90/nu9040328

31. Bataille S, Landrier JF, Astier J, Giaime P, Sampol J, Sichez H, Ollier J, Gugliotta J, Serveaux M, Cohen J, Darmon P (2016) The "dose-effect" relationship between 25 -hydroxyvitamin $D$ and muscle strength in hemodialysis patients favors a normal threshold of $30 \mathrm{ng} / \mathrm{mL}$ for plasma 25-hydroxyvitamin D. J Ren Nutr. 26(1):45-52. https://doi.org/10.1053/j. jrn.2015.08.007 
32. Park CY (2019) Vitamin D in the prevention and treatment of osteoarthritis: from clinical interventions to cellular evidence. Nutrients. 11(2):243-260. https://doi.org/10.3390/nu1 1020243

33. Mermerci Başkan B, Yurdakul FG, Aydın E, Sivas F, Bodur H (2018) Effect of vitamin $D$ levels on radiographic knee osteoarthritis and functional status. Turk J Phys Med Rehabil. 64(1):1-7. https://doi.org/10.5606/tftrd.2018.986

34. McAlindon TE, Felson DT, Zhang Y, Hannan MT, Aliabadi P, Weissman B, Rush D, Wilson PW, Jacques P (1996) Relation of dietary intake and serum levels of vitamin $D$ to progression of osteoarthritis of the knee among participants in the Framingham Study. Ann Intern Med. 125(5):353-359. https://doi.org/10.7326/0003-4819-125-5-199609010-00001

\section{Publisher's Note}

Springer Nature remains neutral with regard to jurisdictional claims in published maps and institutional affiliations.

\section{Submit your manuscript to a SpringerOpen ${ }^{\circ}$ journal and benefit from:}

- Convenient online submission

- Rigorous peer review

- Open access: articles freely available online

- High visibility within the field

- Retaining the copyright to your article

Submit your next manuscript at $\boldsymbol{\nabla}$ springeropen.com 